\title{
Application of the Nonparametric DEA Meta-frontier Approach with Undesirable Outputs in the Case of EU Regions
}

\author{
Jana Hančlová, Lukáš Melecký \\ VŠB-Technical University of Ostrava, Faculty of Economics, Czech Republic
}

\section{Abstract}

Background: The paper focusses on the efficiency evaluation of the EU-28 NUTS 2 regions production process according to the concept of the Regional Competitiveness Index 2013. Objectives: Production units are divided into four groups using the factors of regional competitiveness. Production technology also enables reduction of the undesirable outputs (a negative impact on health and long-term unemployment). Based on the analysis of distance of the production units from the efficiency frontiers, a directional output distance function assuming a constant return to scale is used. This approach thus respects the heterogeneity among the groups of regions. Methods/Approach: The nonparametric meta-frontier Data Envelopment Analysis approach was used in two steps. Firstly, the efficiency evaluation within each group of regions is provided and in the second step the meta-frontier is set down. For the measurement of the gap between the groupfrontier and the meta-frontier, the technology gap ratios are provided. The paper also analyses environmental inefficiencies. Results: The obtained results indicate that a significant improvement of meta-technology ratio holds within the European context. Conclusions: The combination of empirical findings, with respect to technology gaps and environmental technology gaps, supports the evidence that traditional differences of technological frontiers formation are more significant in comparison to group frontiers constitution.

Keywords: competitiveness, directional distance function, efficiency, EU-28 regions, group-frontier, Regional Competitiveness Index 2013, meta-frontier, metatechnology ratio, technology gap inefficiency

JEL classification: R1 1, C61, M1 1

Paper type: Research article

Received: Feb 07, 2016

Accepted: Aug 28, 2016

Acknowledgments: The paper was created under SGS projects (SP2015/106 and SP2015/117) of Faculty of Economics, VŠB-Technical University of Ostrava and Operational Programme Education for Competitiveness - Project No. CZ.1.07/2.3.00/20.0296.)

Citation: Hančlová, J., Melecký, L. (2016), "Application of the Nonparametric DEA Meta-frontier Approach with Undesirable Outputs in the Case of EU Regions", Business Systems Research, Vol. 7, No. 2, pp. 65-77.

DOI: 10.1515/bsrj-2016-0013 


\section{Introduction}

Evaluating the competitiveness of the region pursues not only economic but also social sustainable development. This is reflected in the measurement and evaluation of the efficiency of regions. Also, the output characteristics of the production process of the region include not only desirable outcomes, but the negative outcomes associated with the environment. Rising energy consumption causes increase in carbon dioxide emissions, the imbalance in the labour market may lead to a growth in the number of long-term unemployed, stress and workload growing traffic may cause a higher number of sick economically active population. Regions also differ in terms of development level as well as in the possibility of using their potential (Rehacek, 2011).

For monitoring the efficiency of the production process is then better assess homogeneous groups of regions and compare their comparative advantages and disadvantages. Problematic issue also is the integration of data sets that include characteristics of regions and the ongoing processes in regions, which need a good understanding of broader context; see (Macpherson et al., 2010). To understand these linkages and possible data reduction, multivariate statistical methods can be used as demonstrated e.g. (Tran et al., 2006; Stanickova, 2014).

For examining the efficiency of the production process, homogeneous regions can be applied using a nonparametric approach of Data Envelopment Analysis optimizing the efficiency index based on share of weighted combination of outputs to inputs. Another approach can be the parametric estimation of stochastic limit using Stochastic Frontier Analysis, which has been used by a series of scientific papers on the macro or micro data; see, e.g. (Song et al., 2012; Mandak, 2014).

The paper is focused on efficiency evaluation of EU-28 NUTS 2 regions by selected regional data included in one composite indicator - Regional Competitiveness Index published in 2013 ( $\mathrm{RCl} 2013)$. This synthetic indicator has been finally performed by Annoni et al., 2013. The roots of the $\mathrm{RCl} 2013$ lay down in the most known competitiveness indicator, the Global Competitiveness Index reported by the World Economic Forum; see European Commission, 2013. RCl 2013 presents an index that includes 73 indicators from set of 80 candidate indicators. In the paper, we understand the measuring environmental efficiency as measuring the production environment efficiency just by using selected socio-economic indicators based on competitiveness approach and included undesirable outputs in the form of negative impacts on health and long-term unemployment.

The paper is also focused on the impact of inefficiencies that can be caused by different technological processes of production but also by inefficient decisions of the decision making unit (DMU) in homogeneous groups as compared with the inefficiency based on the meta-frontier (Chiu et al., 2012). The structure of the paper includes an introductory part focused on the competitiveness concept in regional dimension of the European Union. The second part summarizes methodology of nonparametric Data Envelopment Analysis (DEA) approach based on direct distance output function with the involvement of the undesirable outputs and the differences between meta-frontiers and group-frontiers. The third part of the paper describes data, includes the empirical results and discussion on estimation of the meta and group (in)efficiency. The final part of the paper summarizes the main empirical results. 


\section{Methodology}

Efficiency of the production units might be evaluated by the parametric and nonparametric approach. The classic non-parametric approach used in the analysis of the data set is defined by certain combination of outputs and inputs. Unlike the second one - parametric approach evaluates the efficiency through the estimated parameters defined by production function in advance (Hanclova, 2015). Presented paper is focused on non-parametric approach to the efficiency evaluation using production including undesirable and desirable economic, social and infrastructural outputs based on the RCl 2013 approach.

The production function has no assumptions about functional form but looks up for a maximum amount of desired output production uses contracted inputs and undesirable outputs; see e.g. (Macpherson et al., 2010). Furthermore, it is distinguished from the production function with the constant return to scale (CRS) or variable return to scale (VRS) revenue from the range of production function. The paper follows CRS production function. For measurement of the DMU distance from the efficiency frontier the directional output distance function that takes into account the presence of heterogeneity is used.

Directional distance function (DDF) in empirical analysis can be computed in several forms. Färe et al., 2006 use the quadratic DDF and linear programming (LP), Chung et al., 1997 employ the non-parametric approach using DEA - type of LP, Oh, 2010 provides modified DDF to define and decompose the meta-frontier MalmquistLuenberger productivity index, Yuan et al., 2013 use DDF for measuring the environmental efficiency and for the construction of the environmental efficiency index and last but not least Färe et al., 2015 explain DDF in primal and dual spaces and appendixes the parametric and non-parametric form of DDF. Obviously, there are differences between the above mentioned approaches. We employ the latter approach in our paper. Assuming for each production unit a productive process using an input vector $\boldsymbol{x} \in \boldsymbol{R}_{+}^{\boldsymbol{H}}$, to produce a vector of desirable outputs $\boldsymbol{y} \in \boldsymbol{R}_{+}^{N}$ and a vector of undesirable outputs $\boldsymbol{b} \in \boldsymbol{R}_{+}^{\boldsymbol{F}}$ using a production technology given by a set $P$ in the following equation stated by Picazo-Tadeo et al. (2005):

$$
P=\{(\mathbf{x}, \mathbf{y}, \mathbf{b}): \mathbf{x} \text { can produce }(\mathbf{y}, \mathbf{b})\} \text {. }
$$

The set $P$ in the equation (1) includes all feasible technology relationships between inputs and outputs. Oh (2010) states required assumptions for the set $P$ in the form of following axioms assumed on the output side:

- weak disposability of outputs: if $(\mathbf{x}, \mathbf{y}, \mathbf{b}) \in P$ and $0 \leq \alpha \leq 1 \Rightarrow(\mathbf{x}, \alpha \mathbf{y}, \alpha \mathbf{b}) \in P$,

- strong disposability of desirable outputs: if $(\mathbf{x}, \mathbf{y}, \mathbf{b}) \in P$ and $\mathbf{y}^{*} \leq \mathbf{y} \Rightarrow\left(\mathbf{x}, \mathbf{y}^{*}, \mathbf{b}\right) \in P$,

- null-joint production $(\mathbf{x}, \mathbf{y}, \mathbf{b}) \in P$ and $\mathbf{b}=\mathbf{0} \Rightarrow \mathbf{y}=\mathbf{0}$.

We suppose that decrease of bads are costly in the axiom of weak disposability of outputs. The first axiom indicates that the reduction of the undesirable outputs is possible only in the case of the simultaneous reduction of the desirable outputs (Oh, 2010). The second axiom supposes that weak disposability of outputs may not be free activity as stated in classical production theory (Picazo-Tadeo et al., 2005). The desirable outputs that are freely disposed of, may be reduced without the reduction of the undesirable outputs. The third axiom of null-joint production explains that bad and good outputs are jointly produced and if units want to produce a positive amount of desirable outputs some undesirable outputs will be also produced (Picazo-Tadeo et al., 2005). 
We also consider group heterogeneity in production activities and we suppose that production technology of one group is dissimilar from other groups. We expect that there are $G$ different groups $(g=1, \ldots, G)$ in the complete meta-group. Chung et al. (1997) and Picazo-Tadeo et al. (2005) use representation of the joint production of desirable and undesirable outputs by extending the Shepherd's output distance function to the DDF (Shepard, 1970). In our case the distance is defined for the o-thunit in the $g$ group as follows (Oh, 2010):

$$
\overrightarrow{\boldsymbol{D}}_{o}^{g}(\boldsymbol{x}, \boldsymbol{y}, \boldsymbol{b} ; \boldsymbol{g})=\max \left\{\boldsymbol{\beta}^{g}:\left(\boldsymbol{x}, \boldsymbol{y}+\boldsymbol{\beta}^{g} \boldsymbol{g}_{y}, \boldsymbol{b}-\boldsymbol{\beta}^{g} \boldsymbol{g}_{b}\right) \in P\right\},
$$

where $\boldsymbol{g}=\left(\boldsymbol{g}_{\boldsymbol{y}}, \boldsymbol{g}_{\boldsymbol{b}}\right)$ is a direction vector. This distance function looks for maximum of permissible desirable outputs in the $\boldsymbol{g}_{\mathbf{y}}$ direction and the largest attainable reduction of undesirable outputs in the $-\mathbf{g}_{\mathbf{b}}$ direction, which is negative and therefore is the consequence of the reduction of undesirable production output. For simplification we also replace $\overrightarrow{\boldsymbol{D}}_{o}^{g}(\boldsymbol{x}, \boldsymbol{y}, \boldsymbol{b} ; \boldsymbol{g})=\overrightarrow{\boldsymbol{D}}_{o}^{g}(\boldsymbol{x}, \boldsymbol{y}, \boldsymbol{b})$ in this paper. The directional distance function of the o-th DMU in the $g$-th group is represented by $\beta_{o}^{g}$ reported in PicazoTadeo et al. (2005).

We assume to have a sample of $k=1, \ldots, K$ production units, a vector of $h=1, \ldots, H$ inputs to obtain a vector of $m=1, \ldots, M$ desirable outputs and $f=1, \ldots, F$ undesirable outputs. We also suppose that the production set of inputs and outputs is weak disposal. Technology is set under the condition of constant returns to scale (Chiu et al., 2012). Using the directional output distance function, we solve following optimization model:

$$
\begin{aligned}
& \overrightarrow{\boldsymbol{D}}^{g}(\boldsymbol{x}, \boldsymbol{y}, \boldsymbol{b})=\max _{\beta^{g} \geq 0} \beta^{g} \\
& \text { s. t. } \sum_{k=1}^{K} x_{h k} \lambda_{k} \leq x_{h o} \quad h=1,2, \ldots, H \\
& \sum_{k=1}^{K} y_{m k} \lambda_{k} \geq\left(1+\beta^{g}\right) y_{m o} \quad m=1,2, \ldots, M \\
& \sum_{k=1}^{K} b_{f k} \lambda_{k}=\left(1-\beta^{g}\right) b_{f o} \quad f=1,2, \ldots, F \\
& \lambda_{k} \geq 0 \quad k=1,2, \ldots, K,
\end{aligned}
$$

where $\lambda=\left(\lambda_{1}, \lambda_{2}, \ldots, \lambda_{K}\right)$ is a vector of intensity variables. The first constraint (4) provides that actually used input is greater or equal to the resultant input (Yuan et al., 2013). The second constraint (5) provides that actually produced desirable output is smaller or equal to the resultant desirable output. The third constraint (6) expresses that the resultant undesirable output could be higher than what is actually being produced. Symbol $\beta^{g}$ is the technical inefficiency given by distance between the production frontier in $g$-th group and the observation point (Yuan et al., 2013). If $\beta^{g}=0$ then production unit lies on the frontier and is a technically efficient. If $\beta^{g}>0$ then the production unit is inefficient and lies below the frontier. The higher value of $\beta^{g}$ presents the more inefficient production unit (Yuan et al., 2013).

Within using the DDF for the whole group of regions, it can be supposed, that all regional production units have the same level of production technology, which is unreal, and also confirmed by Picazo-Tadeo et al. (2005) or Yuan et al. (2013). O'Donell et al. (2008) proposed the meta-frontier using DEA efficiency approach. 
Chiu et al. (2012) estimated a meta-frontier using of overall groups as well as their group frontiers. These groups should capture the heterogeneity of the production processes better with regard to the technologies or variable production environment of the input resources or desirable and also undesirable outputs. All EU-28 NUTS 2 regions are divided into $1,2, \ldots, G$ groups and for each group is defined $K_{1}, K_{2}, \ldots, K_{G}$ regions and it is valid, that their sum is equal to the number of units in meta group, i.e. $K$. Further, each o-th DMU will be distinguished in one time period of meta-efficiency $M E E_{o}=1-\beta_{o}^{m}$ and group-efficiency $G E E_{o}=1-\beta_{o}^{g}$, where parameters $\beta_{o}^{m}$ or $\beta_{o}^{g}$ are obtained through optimization model in equations (3) to (7), which is analysed for the whole sample or particular group $\mathrm{g}$. The efficiency based on the meta-frontier is less or equal to the efficiency based on the group frontiers (Chiu et al., 2012), i.e. $M E E_{o} \leq G E E_{o}$. We can also measure meta-technology ratio $(M T R)$ as the ratio of the efficiency of the meta-frontier (MEE) and group frontier (GEE); see (Chiu et al., 2012) :

$$
0<M T R_{o}=\frac{M E E_{o}}{G E E_{o}} \leq 1
$$

(8)

If $M T R_{o}$ is closed to 1 then the technology heterogeneity is very low and the efficiency of group's frontiers is closer to the meta-frontier (Chiu et al., 2012). The $M T R_{o}$ expresses that $D M U_{o}$ in group-specific frontiers differ by technology heterogeneity between the two specific frontiers and the source of the inefficiency of the meta-frontier inefficiency cannot be detected (Chiu et al., 2012). There is a possibility to decomposed the inefficiency $D M U_{o}$ into managerial inefficiency $\left(G M I_{o}\right)$ of group-specific frontiers and technology gap inefficiency $\left(T G I_{o}\right)$. The $T G I_{o}=G E E_{o} \cdot\left(1-M T R_{o}\right)$ is given by the inefficiency of the $D M U_{\circ}$ in group-specific frontiers and the reason for this inefficient form is the technical gap between the group-specific frontiers and meta-frontier. The $G M I_{o}=\left(1-G E E_{o}\right)=\beta_{o}^{g}$ is the inefficiency of the $D M U_{o}$ in group-specific frontiers and arises because of lack of desirable output and surplus of undesirable output and input (Chiu et al., 2012).The above reasons presents a managerial failure of production processes management of the $D M U_{o}$. The last ratio $M_{T}$ o measures the environmental inefficiency based on the meta-frontier $M T I_{o}=T G I_{o}+G M I_{o}$.

\section{Results and Discussion}

The data set for empirical analysis was collected from regional statistics database of Eurostat and from annexes of RCl 2013 draft report (European Commission, 2013). The whole tested sample includes 258 NUTS 2 regions instead of 276 in the whole EU28 countries under current NUTS 2013 classification because of the unavailability of data for 18 NUTS 2 regions in Germany, Spain, France, Greece, Portugal, Romania and Croatia.

All selected RCI 2013 indicators were collected between years 2006 and 2011 and values have been normalized by Z-scores. The distribution of $\mathrm{RCl} 2013$ scores are between 1.5 (highest level) and (-1.5) (lowest level). Zero value of $\mathrm{RCl} 2013$ shows the average value of regional competitiveness. For the purpose of evaluation of metaefficiency and group-efficiency of EU-28 NUTS 2 regions based on concept of RCl 2013 - 10 indicators of inputs have been selected $\left(x_{1}, \ldots, x_{10}\right), 4$ desirable indicators of outputs $\left(y_{1}, \ldots, y_{4}\right)$ and 3 undesirable indicators of outputs $\left(b_{1}, b_{2}\right.$ and $\left.b_{3}\right)$ have been 
chosen. Selected dataset of RCI 2013 indicators includes 17 indicators placed in 11 pillars of RCl 2013 (see Table 1).

Selected dataset of $\mathrm{RCl} 2013$ indicators in Table 1, thus include 17 indicators. On the side of input indicators, the RCl 2013 pillar Quality of Institutions includes (1) Corruption, which measures perception of corruption in public services, especially in the local public school and healthcare systems in reference year 2009 and (2) Rule of Law, measures quality and fairness of local police force in reference year 2009.

The $\mathrm{RCl} 2013$ pillar Infrastructure includes (3) Motorway potential accessibility, which presents weighted ratio of population living in surrounding regions and travel time along motorways in reference year 2010, (4) Railway potential accessibility, describes weighted ratio of population living in surrounding regions and travel time along railways in reference year 2010 and (5) Number of passenger flights, displays daily amount of passenger flights (accessible within 90' drive) in reference year 2010.

The $\mathrm{RCl} 2013$ pillar Higher Education and Lifelong Learning is presented by (6) Accessibility to universities, it describes ratio of total population living at more than 60 minutes from the nearest university in the reference year 2006.

The RCI 2013 pillar Labour Market Efficiency is presented by (7) Labour productivity that is expressed by GDP per person employed in industry and services (Index, EU-27 $=100$ ) in reference year 2009. The RCl 2013 pillar Technological Readiness presents (8) Households access to broadband described ratio of total households with access to broadband in reference year 2011.

The $\mathrm{RCl} 2013$ pillar Innovation is represented by (9) Knowledge workers that measures knowledge workers as \% out of total employment in reference year 2011 and (10) Total intramural R\&D expenditure presented total R\&D expenditure as \% of GDP in reference year 2009.

On the side of output indicators, the RCl 2013 pillar Market Size presents (11) Potential GDP in PPS, which displays potential market size expressed in GDP (index, EU-27 $=100$ ) in the reference year 2009.

The RCl 2013 pillar Business sophistication is presented by (12) Gross value added (GVA) in the financial, real estate, professional, scientific and support activities as \% of total GVA (K-N sectors) in reference year 2010.

The RCl 2013 pillar Innovation is described by (13) Total patent applications and it indicates number of applications per million inhabitants in average value of reference years 2007-2008.

The RCl 2013 pillar Health is characterized by (14) Healthy life expectancy which indicates number of years of healthy life expected in reference year 2010. As undesirable outputs we chose indicators (15) Road fatalities reversed measured by number of deaths in road accidents per million inhabitants in average value of reference years 2008-2010 and (16) Cancer disease death rate reversed indicates standardized cancer death rate for population under 65 in average value of reference years 2007-2009.

Finally, the RCl 2013 pillar Labour market efficiency is presented by (17) Long-term unemployment reversed which measured long-term unemployment as \% of labour force in reference year 201 1; for details see (European Commission, 2013). 
Table 1

Selected inputs $(\boldsymbol{x})$, desirable $(\boldsymbol{y})$ and undesirable $(\boldsymbol{b})$ outputs of selected regions

\begin{tabular}{|c|c|c|c|c|c|}
\hline Variables & RCI 2013 Pillar & RCI 2013 Indicator & Unit & Mean & $\begin{array}{l}\text { Standard } \\
\text { Deviation }\end{array}$ \\
\hline $\mathbf{x}_{1}$ & Institutions & Corruption & Index & 5.255 & 0.997 \\
\hline $\mathrm{X}_{2}$ & & Rule of Law & Index & 5.228 & 0.937 \\
\hline$x_{3}$ & Infrastructure & $\begin{array}{l}\text { Motorway } \\
\text { potential } \\
\text { accessibility }\end{array}$ & Index & 4.897 & 0.990 \\
\hline $\mathrm{X}_{4}$ & & $\begin{array}{l}\text { Railway potential } \\
\text { accessibility }\end{array}$ & Index & 4.846 & 0.992 \\
\hline$X_{5}$ & & $\begin{array}{l}\text { Number of } \\
\text { passenger flights }\end{array}$ & Number & 4.834 & 0.956 \\
\hline$x_{6}$ & $\begin{array}{l}\text { Higher } \\
\text { Education }\end{array}$ & $\begin{array}{l}\text { Accessibility to } \\
\text { universities }\end{array}$ & $\%$ & 4.886 & 1.124 \\
\hline$x_{7}$ & $\begin{array}{l}\text { Labour Market } \\
\text { Efficiency }\end{array}$ & $\begin{array}{l}\text { Labour } \\
\text { productivity }\end{array}$ & $\begin{array}{l}\text { GDP/person } \\
\text { employed }\end{array}$ & 4.974 & 1.002 \\
\hline $\mathrm{X}_{8}$ & $\begin{array}{l}\text { Technological } \\
\text { Readiness }\end{array}$ & $\begin{array}{l}\text { Households access } \\
\text { to broadband }\end{array}$ & 等 & 5.071 & 1.006 \\
\hline$x_{9}$ & Innovation & $\begin{array}{l}\text { Knowledge } \\
\text { workers }\end{array}$ & $\%$ & 4.940 & 0.967 \\
\hline$x_{10}$ & & $\begin{array}{l}\text { Total intramural } \\
\text { R\&D expenditure }\end{array}$ & $\%$ & 4.890 & 1.051 \\
\hline$y_{1}$ & Market Size & $\begin{array}{l}\text { Potential GDP in } \\
\text { PPS }\end{array}$ & GDP (PPS) & 4.815 & 0.932 \\
\hline$y_{2}$ & $\begin{array}{l}\text { Business } \\
\text { Sophistication }\end{array}$ & GVA (K-N sectors) & $\%$ & 4.780 & 0.964 \\
\hline$y_{3}$ & Innovation & $\begin{array}{l}\text { Total patent } \\
\text { applications }\end{array}$ & Number & 4.944 & 0.954 \\
\hline$y_{4}$ & Health & $\begin{array}{l}\text { Healthy life } \\
\text { expectancy }\end{array}$ & Number & 5.046 & 0.985 \\
\hline$b_{1}$ & Health & Road fatalities & Number & 4.860 & 1.105 \\
\hline$b_{2}$ & & $\begin{array}{l}\text { Cancer disease } \\
\text { death rate }\end{array}$ & $\%$ & 4.994 & 1.053 \\
\hline$b_{3}$ & $\begin{array}{l}\text { Labour Market } \\
\text { Efficiency }\end{array}$ & $\begin{array}{l}\text { Long-term } \\
\text { unemployment }\end{array}$ & $\%$ & 5.169 & 0.987 \\
\hline
\end{tabular}

Note: Own calculation and elaboration

Source: European Commission (2013); Eurostat (2015)

Firstly, selected regions were ranked in ascending order and divided into 4 groups based on the $\mathrm{RCl} 2013$ scores. Zero value of $\mathrm{RCl} 2013$ shows the average value of selected 258 NUTS 2 regions. The new formed groups of selected NUTS 2 regions can be described as follows:

1. Group 1 includes the regions with the minus $\mathrm{RCl} 2013$ value under the first quartile (69 regions). Structure of NUTS 2 regions within the first group is represented mostly by regions in 'new' EU Member States (EU-13) plus regions of Portugal and Greece.

2. Group 2 contains the regions with below-average regional competitiveness compared to the $\mathrm{RCl} 2013$ index scores between the first and second quartile (median) (35 regions). This group is presented only by regions in 'old' EU 
Member States (EU-15) and most of Italian and Spanish regions are included here.

3. Group 3 introduces the regions with above-average $\mathrm{RCl} 2013$ scores compared to the EU-28 and $\mathrm{RCl} 2013$ scores between the second and the third quartile (72 regions). The most variable structure of NUTS 2 regions inEU-15 and EU-13 Member States is presented in this group, especially in the regions of Austria, Cyprus, Germany, Finland, France, Ireland, Spain, Sweden and United Kingdom.

4. The majority of the competitive regions from EU-15 Member States is placed in the Group 4 and the level of $\mathrm{RCl} 2013$ is above the third quartile of $\mathrm{RCl} 2013$ scores (82). There are NUTS 2 regions from Belgium, France, Germany, the Netherland and United Kingdom.

The efficiencies of the group-frontiers and meta-frontier are estimated using optimization model for 258 NUTS 2 regions and further for each group using a free version of $R$ software. Table 2 summarizes the amounts of efficient NUTS 2 regions by the meta-environmental efficiency $(M E E)$ and group environmental efficiency $(G E E)$. For the whole sample the share of the efficient regions reached almost $70 \%$. In the second group there are all NUTS 2 regions defined as efficient. In the other groups, the share of efficiency units is in the range from 91.3 to $98.6 \%$, which is in compliance with other comparative empirical studies focused on EU Member States or regions; see e.g. (Halkos et al., 2015; Barnes et al., 2011).

Table 2

Meta and Group Frontiers Efficiencies of selected EU-28 NUTS 2 Regions

\begin{tabular}{llll} 
& \multirow{2}{*}{ Number of DMUs } & \multicolumn{2}{l}{ Technical Efficiency } \\
\cline { 3 - 4 } & & Number & $\%$ \\
\hline Meta & 258 & 179 & 69.4 \\
\hline Group 1 & 69 & 63 & 91.3 \\
Group 2 & 35 & 35 & 100.0 \\
Group 3 & 72 & 71 & 98.6 \\
Group 4 & 82 & 77 & 93.9 \\
\hline
\end{tabular}

Source: Author's calculation and elaboration

Table 3 completes further descriptive statistics of the efficiency indices for analysed group samples and confirms the following relation: average metaenvironmental efficiency is lesser or equal to the average group-environmental efficiency. The lower average group-efficiency was indicated in the first group of the regions and the highest standard deviations were identified. On the contrary, in the second group the efficiency was almost unitary with the lowest variability inside the group. A share of the efficient units in the fourth group of the regions was in the amount of $0.998 \%$ and variability of the efficiency in the group was lower compared to the second group. The differences between the efficiencies of the meta-frontier and group-frontiers were investigated using non-parametric statistic. We applied the Kruskal-Wallis test using SPSS 22. The results show that the Kruskal-Wallis value is 6.133. We reject the null hypothesis and conclude that the distribution of $M E E$ is not the same across group samples at $5 \%$ level of significance (sig. $=0.105$ ). These results present that the four group-samples differ in population. We also detect statistical significant technology heterogeneity. 
Table 3

Descriptive Statistics of the Meta-frontier and Group-frontiers Efficiencies

\begin{tabular}{llllllll}
\hline $\begin{array}{l}\text { Descriptive } \\
\text { Statistics }\end{array}$ & Group & MEE & GEE & MTR & TGI & GMI & MTI \\
\hline \multirow{3}{*}{ Mean } & 1 & 0.9940 & 0.9980 & 0.9959 & 0.0041 & 0.0020 & 0.0060 \\
\cline { 2 - 7 } & 2 & 0.9969 & 1.0000 & 0.9969 & 0.0031 & 0.0000 & 0.0031 \\
\cline { 2 - 7 } & $\mathbf{3}$ & 0.9913 & 0.9998 & 0.9915 & 0.0085 & 0.0002 & 0.0087 \\
\hline \multirow{3}{*}{$\begin{array}{l}\text { Standard } \\
\text { deviation }\end{array}$} & $\mathbf{1}$ & 0.9888 & 0.9992 & 0.9896 & 0.0104 & 0.0008 & 0.0112 \\
\cline { 2 - 7 } & $\mathbf{2}$ & 0.0150 & 0.0078 & 0.0100 & 0.0099 & 0.0078 & 0.0150 \\
\hline & 4 & 0.0162 & 0.0018 & 0.0158 & 0.0158 & 0.0018 & 0.0162 \\
\hline
\end{tabular}

Source: Author's calculation and elaboration

Conclusions of the Kruskal-Wallis test also confirm the MTR indicator is the lowest for the fourth group with the highest standard deviation. The lowest average level of MTR is for the first group of analysed NUTS 2 regions, but variability is in the group higher compared to the second group.

We can also briefly mention individual results of environmental efficiency of the meta-frontier in various group-samples $\left(M E E_{o}^{g}\right)$. Among the worst efficient NUTS 2 regions belong Groningen, Bremen, South Western Scotland, Zachodniopomorskie and Dolnoślaskie, where the reduction of undesirable outputs and increasing desirable outputs should be at the minimal level of $6 \%$. The following NUTS 2 regions Prov. Oost-Vlaanderen, Pomorskie, Prov. Namur, East Wales, Lorraine and Lietuva should decrease undesirable outputs and increase desirable outputs minimally by $5 \%$. Significant share between the environmental efficiency of the meta-frontier and group-frontier for the above mentioned NUTS 2 regions demonstrates that there is a higher technology heterogeneity of the production process in comparison to the group and meta-frontier. We also analyse boxplots for the environmental efficiency in different group-samples $\left(M E E_{o}^{g}\right)$. Further efficiency and inefficiency indicators are represented by Figure 1 and Figure 2.

Figure 1 represents a significant share between the environmental efficiency of the meta-frontier (MEE) and group-frontier (GEE) for the above mentioned regions. The low value of the indicator meta-technology ratio (MTR) in the range from 0.918 to 0.949 indicates that mainly in case of the following NUTS 2 regions: Bremen, Groningen, South Western Scotland, Prov. Oost-Vlaanderen, Pomorskie, East Wales and Lorraine. There is a higher technology heterogeneity of the production process with in comparison to the group and meta-frontier. A region with a specific production technology may be detected there. 
Figure 1

Efficiencies and MTR for Selected EU-28 NUTS 2 Regions

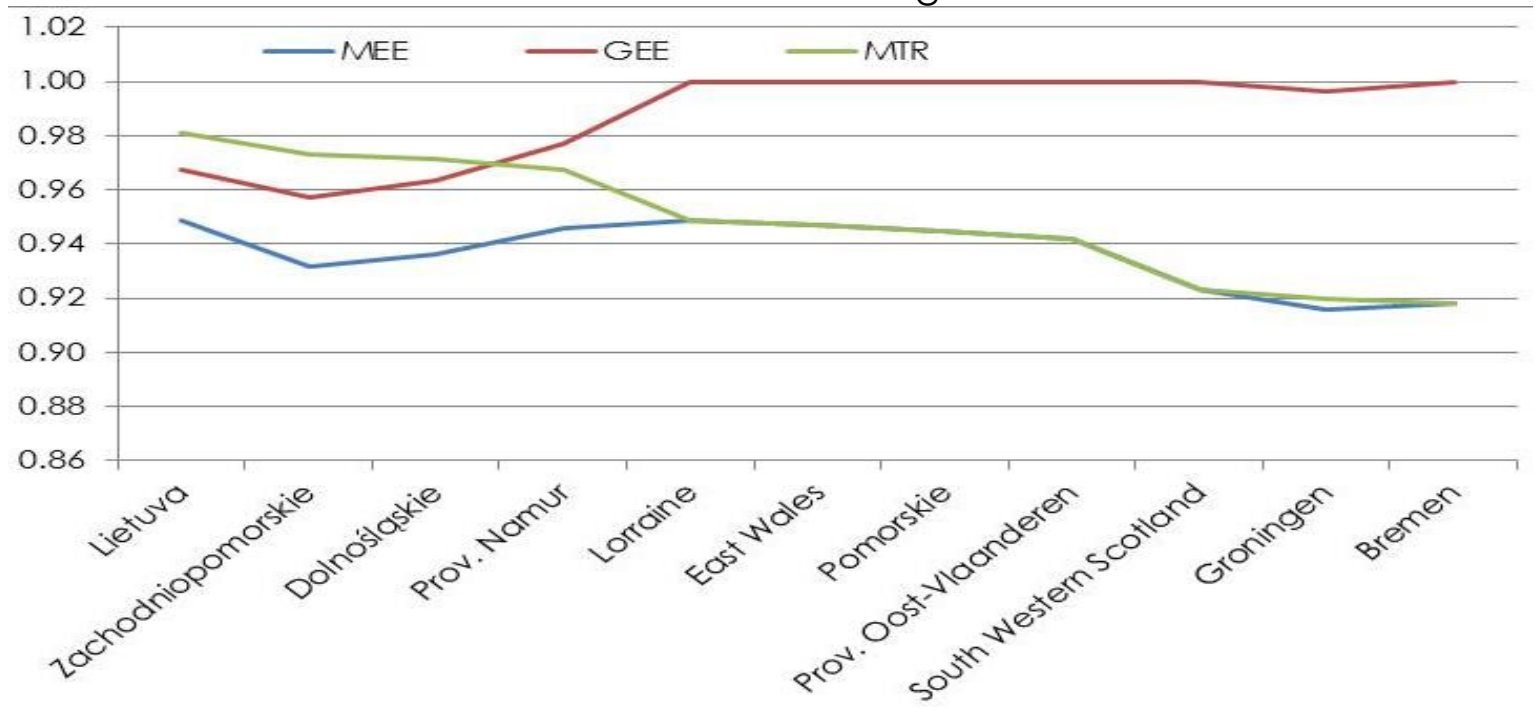

Source: Author's illustration

Figure 2 analyses the inefficiency indicators for the same sample of NUTS 2 regions. TGI presents inefficiency of the DMU in group frontiers justified by excess of undesirable output and input and lack of desirable output. It means, that NUTS 2 regions Bremen, Groningen and South Western Scotland have relatively higher inefficiency in the groups in relation to the TGI values - gradually $0.082,0.081$ and 0.079 values. For the other regions TGI values are lower. It is shown in the indicator GMI -group inefficiency of the o-th DMU group-sample, which is a value of $\beta_{o}^{g}$. If GMI has a positive value and higher than value of TGl, these regions (Prov. Namur, Dolnoślaskie and Zachodniopomorskie) have a problem not only with technological process in relation to the group, but also by excessive inputs and undesirable outputs as well as by deficit of the desirable outputs.

Figure 2

TGI, GMI and MTI for selected EU-28 NUTS 2 Regions

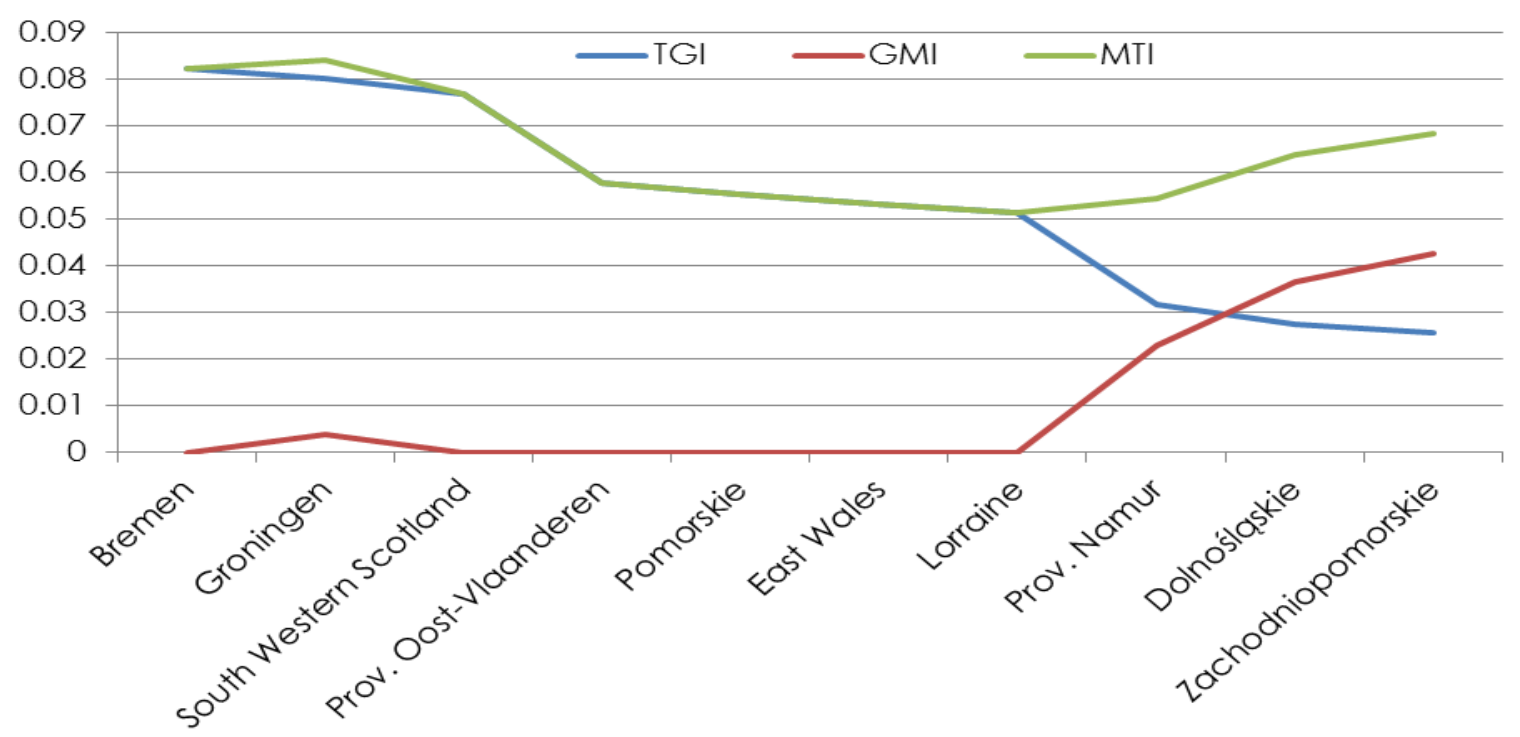

Source: Author's illustration 


\section{Conclusion}

The paper deals with the evaluation of the efficiency of the production process of 258 NUTS 2 regional units in the EU-28 countries in the reference period between years 2006 and 2011. Production process comes out of the concept of input and output indicators by the $\mathrm{RCl} 2013$ methodology focused on evaluation of regional competitiveness.

As benefit of the paper we find an inclusion of selected undesirable outputs in a form of negative impacts on health (e.g. car accidents linked with the increasing traffic load, lifestyle diseases as a cancer following increasing stress situation in work) and long-term unemployment. For the evaluation of the production process, a directional output distance function taking into account the presence heterogeneity.

The objective of the optimization model is maximization of the efficiency within minimal inputs and common increase in desirable outputs and reduction of the undesirable outputs. Another benefit of the paper is the analysis of the relation between meta-frontier and group-frontier, which in case of 258 NUTS 2 regions may distinguish a variable heterogeneity of the production process in the groups. Four groups of NUTS 2 regions were classified on the platform of RCl 2013.

The results of the research might be summarized into the following conclusions.

- Within the analysis of meta-frontier - it was identified, that $69.4 \%$ of the regional production units was efficient.

- Average level of meta-environmental efficiency (MEE) was higher (0.997) in the second group of EU-15 regions with the below-average level of $\mathrm{RCl} 2013$ compared to the EU-28 regions and also variability of the efficiency was the lowest compared to the other groups. On the other hand, the lowest average meta-efficiency (0.989) was indicated by the fourth group of regions in the EU-15 countries with the above-average of $\mathrm{RCl} 2013$ in the $\mathrm{EU}$, but with the highest efficiency variability in the group.

- Average level of the meta technology ratio (MTR) in the groups was in the range from $0.9896-0.9969$ and therefore it seems that heterogeneity between groups is low, but the Kruskal-Wallis test has indicated that four group-samples are presented by dissimilar populations and that technology heterogeneity being present between them at $5 \%$ level of significance.

- Average inefficiency in the group (GMI) was lower than average technology-gap inefficiency (TGI) and in all analysed groups.

- Significant impact on the average environmental inefficiency (MTI) based on the meta-frontier has mainly TGI and also deficit of the desirable output and surplus of inputs and mainly undesirable output.

- Also a region with the highest and the lowest meta-efficiency was detected and the regions might be classified into the groups by the influence TGI or GMI and based on the result a specific regional policy should be devoted to the analysed groups of NUTS 2 regions.

- As important part of the research we consider the analysis of the features of the (in)efficiency in time. 


\section{References}

1. Annoni, P., Dijkstra, L. (2013). EU Regional Competitiveness Index 2013. Luxembourg: Publication Office of the European Union.

2. Barnes, A., Revoredo-Giha, C. (2011), "A Metafrontier Analysis of Technical Efficiency of Selected European Agricultures", paper prepared for presentation at the EAAE 2011 Congress Change and Uncertainty, available at: http://ageconsearch.umn.edu/bitstream/114807/2/Revoredo-

Giha_Cesar_416.pdf (10 July 2016)

3. Chiu, Ching-Ren et al. (2012), "Decomposition of the environmental inefficiency of the meta-frontier with undesirable output", Energy Economics, Vol. 34, pp. 1392-1399.

4. Chung, Y. et al. (1997), "Productivity and undesirable outputs: A directional distance function approach", Journal of Environmental Management, Vol. 51 No. 3, pp. 229-240.

5. European Commission (2013), "Regional Policy Inforegio. Draft EU Regional Competitiveness Index: RCl 2013", available at: http://ec.europa.eu/regional_policy/cs/information/publications/studies/2013/dr aft-eu-regional-competitiveness-index-rci-2013 (28 January 2016)

6. Eurostat (2015) "Data. Regional Statistics by NUTS classification", available at: http://ec.europa.eu/eurostat/data/database (20 December 2015)

7. Färe, R. et al. (2006), "Productivity growth and convergence in the European Union", Journal of Productivity Analysis, Vol. 25, pp. 111-141.

8. Färe, R. et al. (2015). "Distance Functions in Primal and Dual Spaces", in Zhu, J. et al. (Eds.), Data Envelopment Analysis. A Handbook of Models and Methods, Springer, New York, pp. 12-32.

9. Halkos, G. E. et al. (2015), "Regional sustainability efficiency index in Europe: an additive two-stage DEA approach. Berlin: Springer.

10. Hanclova, J. (2015), "Comparison of production performance in information and communication sectors in the EU selected countries", in IDIMT-2015: Information Technology and Society Interaction and Interdependence: 23rd Interdisciplinary Information Management Talks, Sept. 9-11, 2015, Poděbrady, Czech Republic, Trauner, Linz, pp. $111-118$.

11. Macpherson, A.J., Principe, P.P., Smith, E.R. (2010), "A Directional distance function approach to regional environmental-economic assessments", Ecological Economics, Vol. 69, pp. 1918-1925.

12. Mandak, J. (2014), "ICT and technical efficiency of 15 EU countries: A stochastic frontier analysis approach", in Mathematical Methods in Economics, MME 2014: 32nd international conference: September 10-12, Olomouc, Czech Republic, Palacký University, Olomouc, pp. 602-607.

13. O'Donell, C.J., Rao, D.S.P., Battese, G.E. (2008), "Metafrontier Frameworks for Study of Firm-level Efficiencies and Technology ratios", Empirical Economics, Vol. 34, pp. 231-255.

14. Oh, D. (2010), "A Metafrontier Approach for Measuring an Environmentally Sensitive Productivity Growth Index", Energy Economics, Vol. 32, pp. 146-157.

15. Picazo-Tadeo, A.J., Reig-Martínez, E., Hernández_Sancho, F. (2005), "Directional Distance Functions and Environmental Regulation", Energy Economics, Vol. 27, pp. 131-142.

16. Rehacek, P. (2011), "Risk management and FMEA", in Proceedings of the $9^{\text {th }}$ International Conference on Strategic Management and its Support by Information Systems (SMSIS 2011), $5^{\text {th }}$ - $7^{\text {th }}$ September, Čeladná, Czech Republic, Ostrava, VŠB-Technical University of Ostrava, pp. 154-158. 
17. Shephard, R.W. (1970). Theory of Cost and Production Functions, Princeton, Princeton University Press.

18. Song, M. et al. (2012), "Environmental efficiency evaluation based on data envelopment analysis: A review", Renewable and Sustainable Energy Reviews, Vol. 16, pp. 4465-4469.

19. Stanickova, M. (2014), "Competitiveness Factors in Regional Growth: the Case of Central and Eastern European Countries", in Honova, l. et al. (Eds.), Proceedings of the $2^{\text {nd }}$ International Conference on European Integration 2014, VŠB-TUO, Ostrava, pp. 634-643.

20. Tran, L.T. et al. (2006), "A generalized distance measure for integrating multiple environmental assessment indicators", Landscape Ecology, Vol. 21. No. 4, pp. 469-476.

21. World Economic Forum (2013), "The Global Competitiveness Report 2013-2014", WEF, Lausanne.

22. Yuan, P.et al. (2013), "Measuring the environmental efficiency of the Chinese industrial sector: A directional distance function approach", Mathematical and Computer Modelling, Vol. 58, pp. 936-947.

\section{About authors}

Jana Hančlová holds a PhD in Management Theory and Planning and is an Associate Professor in Systems Engineering at the Faculty of Economics, VSBTechnical University of Ostrava. Her research focuses primarily on efficiency and productivity evaluation of decision making units using Data Envelopment Analysis and also Stochastic Frontier Analysis and on macroeconometric modelling of the European Union economies. She is a head of the Department of Systems Engineering at VSB- Technical University of Ostrava. She is also a member of the Czech Economic Society, the Czech Society for Operations Research and the Czech Society for Econometrics. She has been a member of the expert commissions of the Czech Science Foundation for several years. She is a co-author of 12 books, 13 papers in the specialised journals and 78 articles in international conference proceedings. Author can be contacted at jana.hanclova@vsb.cz

Lukáš Melecký holds a PhD in Economics at the Faculty of Economics, VSB-Technical University of Ostrava. His research deals with European integration issues primarily focusing on theoretical aspects of regional disparities, cohesion and competitiveness and also the application of quantitative methods for measuring and evaluation of spatial development, competitiveness and efficiency in national and regional development of the EU Member States and their regions. He is an Assistant Professor and Assistant Head of Department of European Integration at the Faculty of Economics, VŠB-Technical University of Ostrava and also a member of the Czech Economic Society. He is a co-author of 1 book, 5 book chapters, 25 papers in professional journals and more than 70 articles in international conference proceedings. Author can be contacted at lukas.melecky@vsb.cz 